\title{
Catalytic Oxidation of Aryl Alkyl Sulfides Using Immobilized Vanadyl Ions within Nanoreactors of Al-MCM-41
}

\author{
Zamanifar ELHAM, Farzaneh FAEZEH* \\ Department of Chemistry, University of Alzahra, P.O.Box, 1993891176, Vanak, Tehran, Iran
}

\begin{abstract}
VOSO}_{4}$ immobilized within nanoreactors of Al-MCM-41 ( $\left.\mathrm{VO}^{2+} / \mathrm{Al}-\mathrm{MCM}-41\right)$ was synthesized and characterized by X-ray diffraction, Fourier transform infrared spectroscopy, nitrogen adsorption-desorption, and chemical analysis techniques. The prepared $\mathrm{VO}^{2+} / \mathrm{Al}-\mathrm{MCM}-41$ successfully catalyzes the oxidation of aryl alkyl sulfides and up to $99 \%$ conversion and $90 \%$ selectivity for the corresponding sulfoxides were obtained with $\mathrm{H}_{2} \mathrm{O}_{2}$ as oxidant in acetonitrile at room temperature in 30 min.
\end{abstract}

Key words: Al-MCM-4; vanadyl ion; hydrogen peroxide; sulfoxidation

CLC number: O643 Document code: A

Organic sulfoxides are useful synthetic intermediates for the preparation of various chemically and biologically active molecules $[1,2]$. The study of the oxidation of sulfides to sulfoxides with different methodology is an interesting subject. In general, sulfoxides are obtained by the partial oxidation of sulfides with oxidants such as tert-butyl hydroperoxide or $\mathrm{H}_{2} \mathrm{O}_{2}$ [3]. These oxidants are relatively weak and need to be activated by the addition of transition metal ions to produce reactive peroxo species [2-4]. Therefore, many catalytic sulfoxidation reactions have been carried out in the liquid phase in the presence of soluble $\mathrm{Ti}, \mathrm{Mn}, \mathrm{Cr}, \mathrm{Re}$, $\mathrm{W}$, or $\mathrm{V}$ complexes $[2,5-8]$. In recent years, the chemistry of vanadium complexes has attracted considerable attention because of their potential application as catalysts for the oxidation of various organic sulfides [2,9-10]. Easier and more environmentally benign processes can be obtained by heterogenizing the homogeneous catalysts. Several supported metals such as vanadium compounds on $\mathrm{TiO}_{2}$ [11], mesoporous silica [12], USY zeolites [13,14], $\mathrm{VO}_{x} / \mathrm{Al}_{2} \mathrm{O}_{3}$ or $\mathrm{VO}_{x} / \mathrm{SiO}_{2}$ [15], and $\mathrm{VO}(\text { acac })_{2}$ exchanged sulfonic acid resin have been used in sulfoxidation reactions [16].

In this study, we attempted to use $\mathrm{VO}^{2+} / \mathrm{Al}-\mathrm{MCM}-41$ as a stable catalyst for the sulfoxidation of aryl and alkyl sulfides.

\section{Experimental}

\subsection{Immobilization of $\mathrm{VOSO}_{4}$ within Al-MCM-41}

$\mathrm{VOSO}_{4}(0.2 \mathrm{~g})$ in ethanol $(10 \mathrm{ml})$ was added to Al-MCM-41 (1.0 g, synthesized as reported previously [17]) in ethanol $(10 \mathrm{ml})$. The resultant mixture was refluxed for 8 h. The mixture was then filtered and washed with hot ethanol. The percentage of vanadium was determined to be $1.660 \%$ by ICP.

\subsection{General procedure of oxidation of aryl alkyl sulfide}

Typically, a mixture of $0.05 \mathrm{~g}$ of $\mathrm{VO}^{2+} / \mathrm{Al}-\mathrm{MCM}-41$ catalyst and $20 \mathrm{mmol}$ of substrate in $10 \mathrm{ml}$ of acetonitrile was slowly stirred in a round bottom flask. $\mathrm{H}_{2} \mathrm{O}_{2}(30 \%$ aqueous solution, $24 \mathrm{mmol}$ ) was then added to the reaction mixture after a few minutes and further stirred at room temperature. The solid was then filtered and washed with fresh solvent. The filtrate was analyzed by GC and GC-MS.

\subsection{Characterization of the catalyst}

Fourier transform infrared spectroscopy (FT-IR) spectra were recorded on a Bruker Tensor 27 FT-IR spectrometer. Electronic spectra for the solid catalysts were recorded in Nujol on a Perkin Elmer Lambada 35 UV-Vis spectrophotometer. The products were analyzed by GC and GC-MS using an Agilent 6890 Series instrument with an FID detector, a HP-5, 5\% phenylmethylsiloxane capillary, and an Agilent 5973 Network system, a mass selective detector and a HP-5 MS 6989 Network GC system. X-ray powder diffraction (XRD) data were recorded on a Seifert XRD 3003 PTS diffractometer with $\mathrm{Cu} K_{\alpha 1}$ radiation $(\lambda=0.154 \mathrm{~nm})$. Nitrogen adsorption studies were performed at liquid nitrogen temperature using a Quanta chrome Nova 2200, version 7.11 analyzer. Chemical analysis of the samples was carried

Received date: 26 March 2010.

*Corresponding author. Tel: +98-21-88258977; Fax: +98-21-66455291; E-mail: faezeh_farzaneh@yahoo.com; farzaneh@alzahra.ac.ir

Foundation item: Supported by the Research Council of the University of Alzahra, Iran.

English edition available online at ScienceDirect (http://www.sciencedirect.com/science/journal/18722067). 
out using the ICP technique.

\section{Results and discussion}

\subsection{Characterization of the catalyst}

Al-MCM-41 was prepared according to the procedure described previously. Figure 1 shows the XRD pattern of calcined Al-MCM-41. As shown, it has one strong and two weak peaks. All three XRD reflections can be indexed on a hexagonal lattice. The XRD of the calcined Al-MCM-41 is completely consistent with that of the spectrum for Al-MCM-41 [17]. The decrease in the $\mathrm{VO}^{2+} / \mathrm{Al}-\mathrm{MCM}-41$ XRD peak intensities and the decrease in the $d$ value from 3.878 to $3.803 \mathrm{~nm}$ is an indication of the Al-MCM-41 pore surface silanol groups reacting with vanadyl ions (Fig. 1, and Table 1).

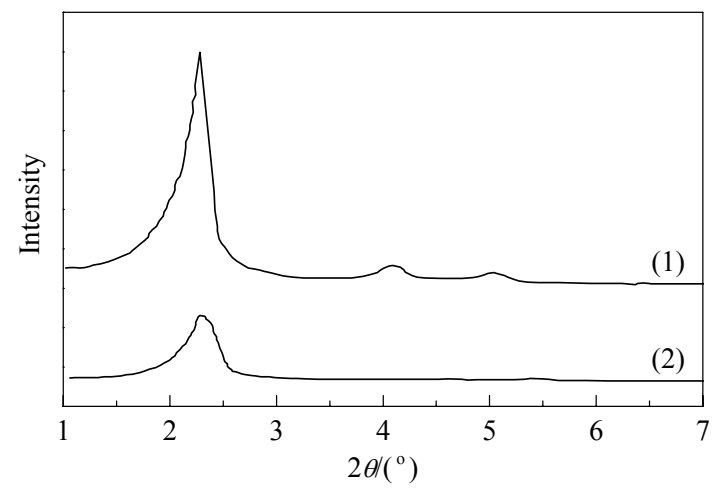

Fig. 1. XRD patterns of calcined Al-MCM-41 (1) and $\mathrm{VO}^{2+} / \mathrm{MCM}-41$ (2).

The $\mathrm{N}_{2}$ adsorption-desorption isotherms of Al-MCM-41, $\mathrm{VO}^{2+} / \mathrm{Al}-\mathrm{MCM}-41$, and used $\mathrm{VO}^{2+} / \mathrm{Al}-\mathrm{MCM}-41$ are shown in Fig. 2. The type IV isotherms [18] indicate that at low relative pressures $p / p_{0}$, adsorption take place as thin layers on the walls (monolayer coverage). In addition, the height of the inflection in the nitrogen adsorption isotherm plots for $\mathrm{VO}^{2+} / \mathrm{Al}-\mathrm{MCM}-41$ is smaller than that of Al-MCM-41. This is attributed to the reduction in pore volume from 1.0740 to $0.9735 \mathrm{~cm}^{3} / \mathrm{g}$, which indicates a decrease in the surface area (Table 1). This effect can be attributed to the

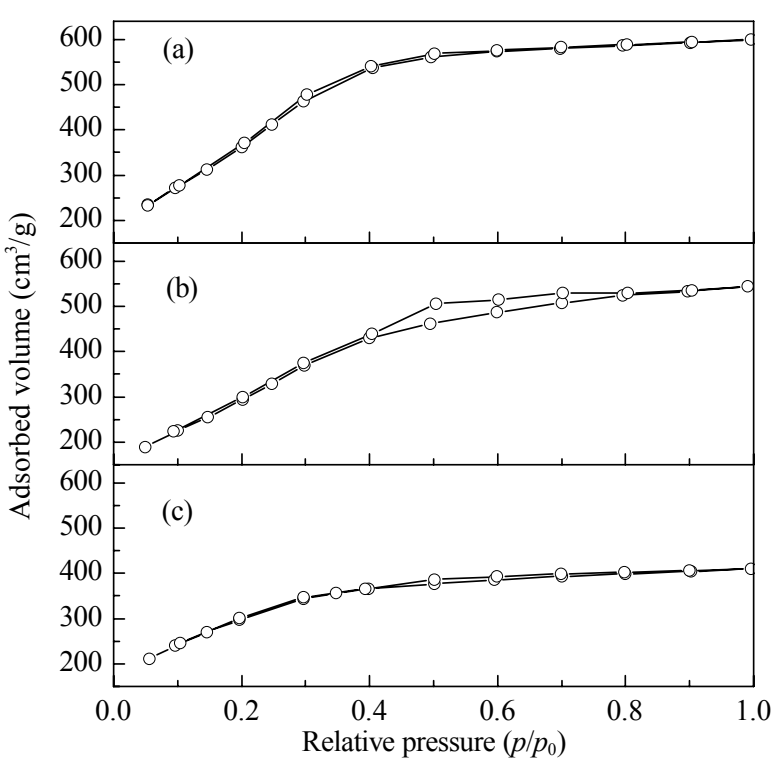

Fig. 2. Nitrogen adsorption-desorption isotherms of Al-MCM-41 (a), $\mathrm{VO}^{2+} / \mathrm{Al}-\mathrm{MCM}-41$ (b), and $\mathrm{VO}^{2+} / \mathrm{Al}-\mathrm{MCM}-41$ after the reaction (c)

inclusion of vanadyl ions in the Al-MCM-41 pores. A surface area and pore volume of $1095 \mathrm{~m}^{2} / \mathrm{g}$ and $0.5148 \mathrm{~cm}^{3} / \mathrm{g}$, respectively, were obtained by $\mathrm{N}_{2}$ adsorption-desorption isotherms (Fig. 2(c)) and reveals that the used catalyst is stable. The small decrease in these parameters might be because of the adsorption of some water and solvent molecules.

The FT-IR spectra of Al-MCM-41 and $\mathrm{VO}^{2+} / \mathrm{Al}-\mathrm{MCM}-41$ are shown in Table 2 . The broad bands around $3422 \mathrm{~cm}^{-1}$ are attributed to surface silanols and adsorbed water molecules. The adsorption bands at 1080-1 100 and $1200-1223 \mathrm{~cm}^{-1}$ are because of the asymmetric stretching vibrations of $\mathrm{Si}-\mathrm{O}-\mathrm{Si}$ bridges, and the band at $950-980 \mathrm{~cm}^{-1}$ arises from $\mathrm{Si}-\mathrm{O}-\mathrm{Al}$ vibrations, $\mathrm{V}-\mathrm{O}-\mathrm{Si}$ symmetric vibrations $[16,19]$ and $\mathrm{V}=\mathrm{O}$ stretching modes.

\subsection{Catalytic activity studies}

The oxidation of methyl phenyl sulfide as a representative substrate with $30 \%$ aqueous $\mathrm{H}_{2} \mathrm{O}_{2}$ was carried out using $\mathrm{VO}^{2+} / \mathrm{Al}-\mathrm{MCM}-41$ as a catalyst. To obtain the optimum

Table 1 Texture parameters of samples taken from XRD and nitrogen adsorption studies

\begin{tabular}{|c|c|c|c|c|c|}
\hline Catalyst & XRD $d$ value (nm) & Lattice parameter (nm) & BET surface area $\left(\mathrm{m}^{2} / \mathrm{g}\right)$ & Pore volume $\left(\mathrm{cm}^{3} / \mathrm{g}\right)$ & Average pore diameter $(\mathrm{nm})$ \\
\hline Al-MCM-41 & 3.878 & 4.478 & 1455 & 1.0740 & 1.972 \\
\hline VO-Al-MCM-41 & 3.803 & 4.391 & 1202 & 0.9735 & 1.950 \\
\hline
\end{tabular}

Table 2 FT-IR band assignments corresponding to the wavenumbers obtained for Al-MCM-41 and immobilized vanadyl ions within the nanoreactors of Al-MCM-41

\begin{tabular}{lccc}
\hline Catalyst & $v \mathrm{OH}(\mathrm{Si}-\mathrm{OH}) / \mathrm{cm}^{-1}$ & $v_{\text {as }}(\mathrm{Si}-\mathrm{O}-\mathrm{Si}) / \mathrm{cm}^{-1}$ & $v_{\text {as }}(\mathrm{Si}-\mathrm{O}-\mathrm{Si}) /(\mathrm{Si}-\mathrm{O}-\mathrm{V}) / \mathrm{cm}^{-1}$ \\
\hline Al-MCM-41 & 3422 & 1080,1223 & 960 \\
VO-Al-MCM-41 & 3424 & 1091,1223 & 802 \\
\hline
\end{tabular}


reaction time, the oxidation reactions were carried out over different times. The results are presented in Table 3. As seen in Table 3, about $87 \%$ of the methyl phenyl sulfide was converted into sulfoxide and sulfone with $85 \%$ and $15 \%$ selectivities, respectively, during $30 \mathrm{~min}$ of reaction time.

Table 3 Effect of time on the oxidation of phenyl methyl sulfide in acetonitrile in the presence of $\mathrm{VO}^{2+} / \mathrm{Al}-\mathrm{MCM}-41$

\begin{tabular}{ccccc} 
Entry & $\begin{array}{c}\text { Time } \\
(\mathrm{min})\end{array}$ & $\begin{array}{c}\text { Conversion } \\
(\%)\end{array}$ & $\begin{array}{c}\text { Sulfoxide } \\
\text { selectivity (\%) }\end{array}$ & $\begin{array}{c}\text { Sulfone } \\
\text { selectivity (\%) }\end{array}$ \\
\hline 1 & 10 & 58 & 48 & 52 \\
2 & 20 & 75 & 56 & 45 \\
3 & 30 & 87 & 85 & 15 \\
$4^{\mathrm{a}}$ & 30 & 66 & 80 & 20 \\
5 & 60 & 87 & 84 & 16 \\
$6^{\mathrm{b}}$ & 30 & 14 & 59 & 41 \\
\hline
\end{tabular}

Reaction conditions: catalyst $0.05 \mathrm{~g}$, substrate $20 \mathrm{mmol}, \mathrm{H}_{2} \mathrm{O}_{2} 24 \mathrm{mmol}$, room temperature. ${ }^{\mathrm{a}}$ Catalyst $0.10 \mathrm{~g} .{ }^{\mathrm{b}} \mathrm{A}$ blank reaction.

Furthermore, the use of about $0.05 \mathrm{~g}$ catalyst was shown to give a substrate conversion of $85 \%$. A further increase in the amount of catalyst by $0.10 \mathrm{~g}$ led to a decrease in conversion to $66 \%$. Increasing the amount of catalyst to beyond the optimum amount increases the available catalyst surface area and thus creates a suitable medium for the adsorption of guest molecules (either substrates or products). This in turn may result in a decrease in the total conversion.

A blank reaction under similar conditions with methyl phenyl sulfide resulted in a $14 \%$ conversion with $59 \%$ and $41 \%$ selectivity for the sulfoxide and sulfone, respectively. Thus, running the oxidation reaction in the presence of $\mathrm{VO}^{2+} / \mathrm{Al}-\mathrm{MCM}-41$ as a catalyst not only enhances the methyl phenyl sulfide conversion but also improves its selectivity toward the formation of sulfoxides.

We then examined a range of sulfides having various $R$ groups that were either aromatic or aliphatic and were attached to the sulfur atom under oxidation conditions. The results are listed in Table 4 . Table 4 reveals that dimethylsulfide with $99 \%$ conversion and diphenyl sulfide with $4 \%$ conversion show the most and the least oxidation reactivity, respectively, at room temperature but the conversion of diphenyl sulfide increased to $98 \%$ under reflux conditions.

The recyclability of $\mathrm{VO}^{2+} / \mathrm{Al}-\mathrm{MCM}-41$ as a catalyst was investigated for the dimethylsulfide reaction in a typical experiment where the reaction mixture was filtered and the catalytic reaction was repeated under similar conditions after activating the catalyst by washing with acetonitile and drying at $100{ }^{\circ} \mathrm{C}$. No appreciable loss in catalytic activity was observed and this suggests that the active species is still present in the Al-MCM-41 nanopores. On the other hand,
Table 4 Oxidation of aryl alkyl sulfides with $\mathrm{H}_{2} \mathrm{O}_{2}$ in the presence of $\mathrm{VO}^{2+} / \mathrm{Al}-\mathrm{MCM}-41$

\begin{tabular}{|c|c|c|c|c|}
\hline Substrate & $\begin{array}{c}\text { Conversion } \\
(\%)\end{array}$ & $\begin{array}{c}\text { Sulfoxide } \\
\text { selectivity } \\
(\%)\end{array}$ & $\begin{array}{c}\text { Sulfone } \\
\text { selectivity } \\
(\%)\end{array}$ & $\mathrm{TON}^{\mathrm{a}}$ \\
\hline & 87 & 85 & 15 & 1088 \\
\hline & 4 & 84 & 16 & 1025 \\
\hline & $84^{\mathrm{b}}$ & 100 & - & 50 \\
\hline & 98 & 66 & 34 & 1225 \\
\hline & $\approx 99$ & 90 & 10 & 1238 \\
\hline & $95^{\mathrm{c}}$ & 90 & 10 & - \\
\hline & $20^{\mathrm{d}}$ & 100 & - & - \\
\hline & $10^{\mathrm{e}}$ & 100 & - & - \\
\hline
\end{tabular}

Reaction conditions: catalyst $0.05 \mathrm{~g}$, substrate $20 \mathrm{mmol}, \mathrm{H}_{2} \mathrm{O}_{2} 24$ mmol, solvent acetonitrile $10 \mathrm{ml}$, room temperature, $30 \mathrm{~min}$.

${ }^{\mathrm{a}} \mathrm{TON}$ is the mmol of product to mmol of vanadium present in the catalysts. ${ }^{b}$ Under reflux conditions for $3 \mathrm{~h}$. ${ }^{\mathrm{c}}$ Used catalyst. ${ }^{\mathrm{d}}$ In the presence of Al-MCM-41 catalyst. ${ }^{\mathrm{e}}$ No catalyst was used.

the filtrate did not show any activity when it was subjected to another $30 \mathrm{~min}$ reaction with fresh oxidant and substrate. An ICP determination of the vanadium catalyst found $1.660 \%$ and $1.559 \%$ before and after the reaction, respectively. The vanadium content of the filtrate solution was found to be below the ICP detection limit. These results clearly demonstrate the heterogeneous nature of the sulfoxidation reaction.

We propose a mechanism based on the chemistry of peroxovanadium as reported previously [10]. The peroxo species is obtained in situ by the interaction of the catalyst with hydrogen peroxide. A subsequent transfer of electrophilic oxygen from the peroxometal species to the nucleophilic sulfide leads to the formation of sulfoxide with the eventual regeneration of the catalyst [20].

Compared with the reported procedures [14,15,21], the use of $\mathrm{VO}^{2+}$ without using any ligand plus the heterogeneous nature of the catalysis system free of metal ion leaching is the novelty of our method. The diversity of the sulfide used in this work and dimethyl sulfide in particular for the synthesis of dimethyl sulfoxide (DMSO) is of particular importance in this research.

\section{Conclusions}

We found that $\mathrm{VO}^{2+} / \mathrm{Al}-\mathrm{MCM}-41$ promotes the sulfoxidation of methyl phenyl, dimethyl, tollyl methyl, and diphenyl sulfides towards sulfides and sulfones with ecofriendly oxidants under mild conditions. The reactivity of sulfides to- 
ward sulfoxidation increases by increasing the electron donating ability of the organic sulfide groups. The sulfoxidation of tollyl methyl and dimethyl sulfide occurred with $98 \%$ and $99 \%$ conversion, respectively, and the absence of leaching during the course of these reactions is of fundamental importance and should be emphasized.

\section{References}

1 Carreno M C. Chem Rev, 1995, 95: 1717

2 Kaczorowska K, Kolarska Z, Mitka K, Kowalski P. Tetrahedron, 2005, 61: 8315

3 Adam W, Malisch W, Roschmann K J, SahaMoller C R, Schenk W A. J Organomet Chem, 2002, 661: 3

4 Punniya Murthy T, Rout L. Coord Chem Rev, 2008, 252: 134

5 Mancka M, Plass W. Inorg Chem Commun, 2007, 10: 677

6 Maurya M R. Coord Chem Rev, 2003, 237: 163

7 Ligtenbarg A G J, Hage R, Feringa B L. Coord Chem Rev, 2003, 237: 89

8 Bolm C. Coord Chem Rev, 2003, 237: 245

9 Anisimov A V, Fedorova E V, Lesnugin A Z, Senyavin V M, Aslanov L A, Rybakov V B, Tarakanova R V. Catal Today,
2003, 78: 319

10 Smith T S, Pecoraro V L. Inorg Chem, 2002, 41: 6754

11 Kantam M L, Neelima B, Reddy C V, Chaudhuri M K, Dehury S K. Catal Lett, 2004, 95: 19

12 Trukhan N N, Derevyankin A Y, Shmakov A N, Paukshtis E A, Kholdeeva OA, Romannikov V N. Microporous Mesoporous Mater, 2001, 44-45: 603

13 Fuerte A, Iglesias M, Sanchez F, Corma A. J Mol Catal A, 2004, 211: 227

14 Maurya M R, Chandrakar A K, Chand S. J Mol Catal A, 2007, 278: 12

15 Moussa N, Fraile J M, Ghorbel A, Mayoral J A. J Mol Catal A, 2006, 255: 62

16 Prasanth K L, Maheswaran H. J Mol Catal A, 2007, 268: 45

17 Zanjanchi M A, Asgari S. Solid State Ionics, 2004, 171: 277

18 Lynch J. Physico-Chemical Analysis of Industrial Catalysts. Paris: Technip, 2001. 7

19 Shylesh S, Singh A P. Microporous Mesoporous Mater, 2006, 94: 127

20 Butler A, Clague M J, Meister G E. Chem Rev, 1994, 94: 625

21 Maurya M R, Chandrakar A K, Chand S. J Mol Catal A, 2007, 263: 227 